\title{
Commentary: Looking for the ideal pulmonary valve
}

\author{
Gianluigi Perri, $\mathrm{MD}, \mathrm{PhD}$, and \\ Lorenzo Galletti, MD, PhD
}

In this issue of the Journal, Kwak and colleagues ${ }^{1}$ analyzed long-term results of 2 different types of bioprosthetic valves (porcine and pericardial) used in the pulmonary position in patients after repair of congenital heart diseases. At a 15year follow-up, the authors found a superiority of porcine valves over pericardial valves in terms of prosthetic valve failure $(69.4 \%$ vs $41.8 \%)$ and reoperation free rate $(81.3 \%$ vs $60.6 \%)$. They also identified different modes of failure, with stenosis typical for porcine valves and stenosis with regurgitation more common in pericardial valves, and suggested that this would be a consequence of more extensive disease.

Chronic pulmonary regurgitation is a common sequela of right ventricular outflow tract (RVOT) intervention for congenital cardiac lesions, and pulmonary valve replacement (PVR) is often required to prevent irreversible right ventricular (RV) dysfunction. Today, even though transvenous PVR is an accepted mode of treatment, surgical implantation of bioprosthetic valves remains essential in patients with larger RVOTs not amenable to percutaneous treatment.

Better tissue selection and improved fixation technology have significantly increased the durability of bioprosthetic valves, which are preferred over mechanical valves because they avoid the long-term harmful effects of anticoagulation. In the pulmonary position, bioprostheses are almost universally implanted because of concerns about mechanical valve thrombosis secondary to low-pressure circulation in the right heart. ${ }^{2}$ Further advantages of bioprostheses are that they can be crossed by catheter for pulmonary artery

\footnotetext{
From the Pediatric Cardiac Surgery Unit, Department of Pediatric Cardiology and Cardiac Surgery, Bambino Gesù Children Hospital, Rome, Italy.

Disclosures: The authors reported no conflicts of interest.

The Journal policy requires editors and reviewers to disclose conflicts of interest and to decline handling or reviewing manuscripts for which they may have a conflict of interest. The editors and reviewers of this article have no conflicts of interest.

Received for publication April 27, 2020; revisions received April 27, 2020; accepted for publication April 28, 2020; available ahead of print May 11, 2020.

Address for reprints: Lorenzo Galletti, MD, PhD, Cardiac Surgery Unit, Department of Pediatric Cardiology and Cardiac Surgery, Bambino Gesù Children Hospital, Rome, Italy (E-mail: lorenzo.galletti@opbg.net).

J Thorac Cardiovasc Surg 2020;160:485-6

$0022-5223 / \$ 36.00$

Copyright (C) 2020 by The American Association for Thoracic Surgery

https://doi.org/10.1016/j.jtcvs.2020.04.135
}

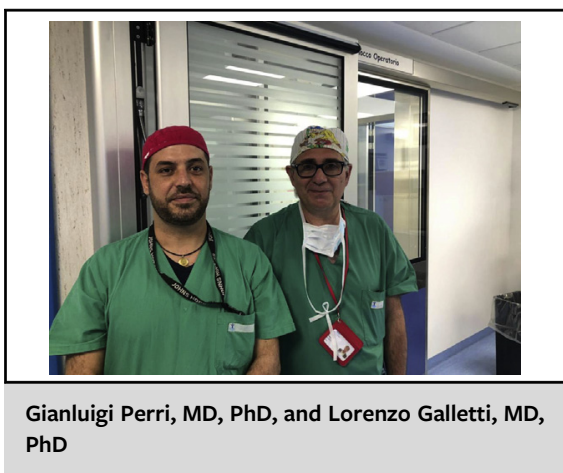

CENTRAL MESSAGE

The long-term performance of bioprostheses in the pulmonary position is limited, especially when implanted in younger patients. Porcine valves seem to have a slight advantage in term of valve deterioration, but no definitive data are available. A randomized prospective study is needed to compare the results between different types of bioprostheses at the pulmonary position.

dilation and stenting, which are not uncommon in these patients, and represent landing zones for valve-in-valve procedures.

However, different studies have shown that durability of bioprosthetic valves in the pulmonary position, especially in younger patients, is suboptimal, due mainly to dystrophic leaflet calcification that causes valve stenosis and regurgitation. ${ }^{3-6}$ In addition, in the present study, younger age, along with prosthesis size, were identified as predictors of failure. ${ }^{1}$

The reported 10-year cumulative incidence of reintervention after PVR ranges from $10 \%$ to $35 \%,{ }^{7,8}$ but these data almost certainly underestimate the true risk of valve dysfunction, because the timing of PVR is influenced by several factors, including symptoms, degree of RV dilatation and dysfunction, arrhythmias, and the risk of periprocedural reintervention. Therefore, the interval from implantation to reintervention might not always be an accurate reflection of prosthetic valve longevity. 
We should also consider that the prosthetic valves used in the pulmonary position were originally designed for the aortic position and thus in the RVOT are exposed to hemodynamic conditions characterized in particular by lower pressure and flow velocity. Moreover, despite the current documented inferior durability of stentless valves, the long-term durability of different stented valves remains controversial. Jang and colleagues ${ }^{10}$ observed early PVD in stented bovine pericardium valves, and Lee and colleagues $^{3}$ reported the long-term durability of this type of bioprosthesis with respect to porcine valves.

In their article, Kwak and colleagues identify younger age at implantation as a primary risk factor for valve degeneration. According to Chen and colleagues, ${ }^{11}$ this association can be explained both by the natural tendency toward overgrowth and by the effect of active calcium metabolism in young children. Furthermore, as the authors suggest, the greater immunologic activity of young patients may contribute to accelerated valve failure.

Interestingly, the authors describe the macroscopic alterations at the level of the prosthetic leaflet (degeneration, calcification, and inflammatory response) that allow better definition of the pathological mechanisms related to failure. In particular, the authors suggest that the lower pressure of the pulmonary circulation, different from that in the aortic position, appears to be insufficient to maintain ideal opening and closing of pericardial valve leaflets, with differences in leaflet stress characteristics that might affect durability. In contrast, porcine valve leaflets valve may maintain their configuration and mobility even with the lower-pressure system and should be preferred to avoid medium and long-term bioprosthesis failure. Further studies and likely prospective trials are needed to better understand the strategies for increasing bioprosthetic valve longevity.

\section{References}

1. Kwak JG, Bang JH, Cho S, Kim ER, Shih BC, Lee CH, et al. Long-term durability of bioprosthetic valves in pulmonary position: pericardial versus porcine valves. J Thorac Cardiovasc Surg. 2020;160:476-84.

2. Baumgartner H, Bonhoeffer P, De Groot NM, de Haan F, Deanfield JE, Galie N, et al Task Force on the Management of Grown-up Congenital Heart Disease of the European Society of Cardiology (ESC), Association for European Paediatric Cardiology (AEPC), ESC Committee for Practice Guidelines (CPG). ESC guidelines for the management of grown-up congenital heart disease (new version 2010). Eur Heart J. 2010;31:2915-57.

3. Lee C, Park CS, Lee CH, Kwak JG, Kim SJ, Shim WS, et al. Durability of bioprosthetic valves in the pulmonary position: long-term follow-up of 181 implants in patients with congenital heart disease. J Thorac Cardiovasc Surg. 2011;142: $351-8$.

4. Kwak JG, Lee JR, Kim WH, Kim YJ. Mid-term results of the Hancock II valve and Carpentier-Edward Perimount valve in the pulmonary portion in congenital heart disease. Heart Lung Circ. 2010;19:243-6.

5. Discigil B, Dearani JA, Puga FJ, Schaff HV, Hagler DJ, Warnes CA, et al. Late pulmonary valve replacement after repair of tetralogy of Fallot. J Thorac Cardiovasc Surg. 2001;121:344-51.

6. Caldarone CA, McCrindle BW, Van Arsdell GS, Coles JG, Webb G, Freedom RM, et al. Independent factors associated with longevity of prosthetic pulmonary valves and valved conduits. J Thorac Cardiovasc Surg. 2000;120: 1022-30.

7. Nomoto R, Sleeper LA, Borisuk MJ, Bergerson L, Pigula FA, Emani S, et al. Outcome and performance of bioprosthetic pulmonary valve replacement in patients with congenital heart disease. J Thorac Cardiovasc Surg. 2016;152:1333-42.e3.

8. Sabate Rotes A, Eidem BW, Connolly HM, Bonnichsen CR, Rosedahl JK, Schaff HV, et al. Long-term follow-up after pulmonary valve replacement in repaired tetralogy of Fallot. Am J Cardiol. 2014;114:901-8.

9. Egbe AC, Connolly HM, Miranda WR, Dearani JA, Schaff HV. Outcomes of bioprosthetic valves in the pulmonary position in adults with congenital heart disease. Ann Thorac Surg. 2019;108:1410-5.

10. Jang W, Kim YJ, Choi K, Lim HG, Kim WH, Lee JR. Mid-term results of bioprosthetic pulmonary valve replacement in pulmonary regurgitation after tetralogy of Fallot repair. Eur J Cardiothorac Surg. 2012;42:e1-8.

11. Chen PC, Sager MS, Zurakowski D, Pigula FA, Baird CW, Mayee JE Jr, et al. Younger age and valve oversizing are predictors of structural valve deterioration after pulmonary valve replacement in patients with tetralogy of Fallot. J Thorac Cardiovasc Surg. 2012;143:352-60. 